\title{
Delineation of Basin Geometry within Parts of Northern Anambra Basin, Nigeria: An Aeromagnetic Approach
}

\author{
Odoh, Okwuchukwu Peter ${ }^{1} \quad$ Ezeh, Chukwudi Chris ${ }^{2} \quad$ Usman, Ayatu Ojonugwa ${ }^{3}$ \\ Okanya, Obianuju Sophia ${ }^{2}$ Chima, Chizoba Joshua ${ }^{3}$ \\ 1.Department of Physics, Michael Okpara University, Umudike, Abia State \\ 2.Department of Geology and Mining, Enugu State University of Science and Technology, Enugu \\ 3.Department of Applied Geophysics, AE-Federal University, Ndufu-Alike Ikwo, Ebonyi State
}

\begin{abstract}
Total field aeromagnetic anomalies over Ankpa and environs Northern Anambra basin (sheets 269, 270,288 and 289) were acquired, digitized and analyzed with a view of mapping the predominate geologic structures, demarcate the basin geometry, estimation of the basal depth (sedimentary thicknesses) and produce an ideological magnetic potential map of the area. The residual map is noticeable by spirogyra and uneven shaped bodies characterized by different magnetic values ranging from lows, highs and medium magnetic intensities within the range of $-91.50 \mathrm{nT}$ to $41.60 \mathrm{nT}$. qualitative study of the residual anomalous map shows the presence of basement rocks intrusion around north and south-western portion of the area. Downward continuation map reveals the structures are orienting in NE-SW and NW-SE direction and these conforms with trend of structures in Northern Anambra basin and by extension lower Benue trough. Result from quantitative interpretation shows two basal depth sources, the deeply seated magnetic source which ranges from 1.76 to $4.50 \mathrm{~km}$ and the near surface seated magnetic sources, ranging from 0.50 to $1.76 \mathrm{~km}$. The shallower magnetic basal depth sources are believed to be as a result of basement intrusion or magnetized ore bodies inside the sedimentary infillings. 3-D surface map reveals a depression at the middle part of the study area indicating thicker sediments which trend northwest-southeast direction while the eastern and southern parts have shallower sedimentary thicknesses. The high pass filter map depicts anomalies between the range -16.0nT and 8.7nT.
\end{abstract}

Keywords:Spectral Analysis, Magnetic Potential, Basin Configuration, High-pass-filter, DownwardContinuation.

DOI: $10.7176 / \mathrm{JEES} / 11-4-04$

Publication date: April $30^{\text {th }} 2021$

\section{Introduction}

Magnetic surveying is used in the investigation of the subsurface geology of an area. "This is achieved by delineating rocks or minerals that show unusually characteristic since they will reveal themselves as anomalous magnetic body which are normally produced by magnetic susceptibility variations of the underlying rocks" (Biswas,2017). Magnetic anomaly traps usually reveal differences in Earth's geomagnetic field from the subsurface rocks magnetic properties. Most rock forming minerals have small to very little magnetic susceptibilities and basically they are non-magnetic, some rock types have adequate magnetic minerals (mostly magnetite) to form identifiable anomalous magnetic bodies. Sedimentary rocks have a low magnetic susceptibility values, whereas, metamorphic and basement igneous rocks have the utmost magnetic susceptibilities values (Likkason., 2007).

Spectral analysis introduction in quantitative study of space data is a reliable geophysical method that for estimating of the basal depth [Spector and Grant, 1970]. The study aimed at the delineation of potential field aeromagnetic anomalies in an attempt to review the Basal geometry of the area.

There is little or no subsurface geophysical mapping carried out within the study area and only a very minute effort has been made to understand the comprehensive correlation between structural features detected on the ground and those extending into the subsurface. Hence, this study involves the delineation of the basin geometry using aeromagnetic data. This will determine the magnetic potential and basin configuration of the study area. This is realized through; Qualitative interpretation of the anomalous aeromagnetic map to reveal structural features such as faults, and fractures; determine the basal depth using; geologic modelling of the depth to magnetic basement; construct the basement topography; to get 3-Dimensional geometry of the Basin and model geologic anomalies.

\section{Location and Geologic Setting}

The study area Northern Anambra Basin, Nigeria covering some parts of Enugu and Kogi States. The study area encloses some communities like Ankpa, Oturkpo, Igumale and Ejekwe lying between latitude $6^{0} 30^{1} \mathrm{~N}$ to $7^{0}$ $30^{1} \mathrm{~N}$ and Longitude $7^{0} 30^{1} \mathrm{E}$ to $8^{0} 30^{1} \mathrm{E}$. The studied area covers about 12100 square kilometers ${ }^{2}$ (Fig. 1). 


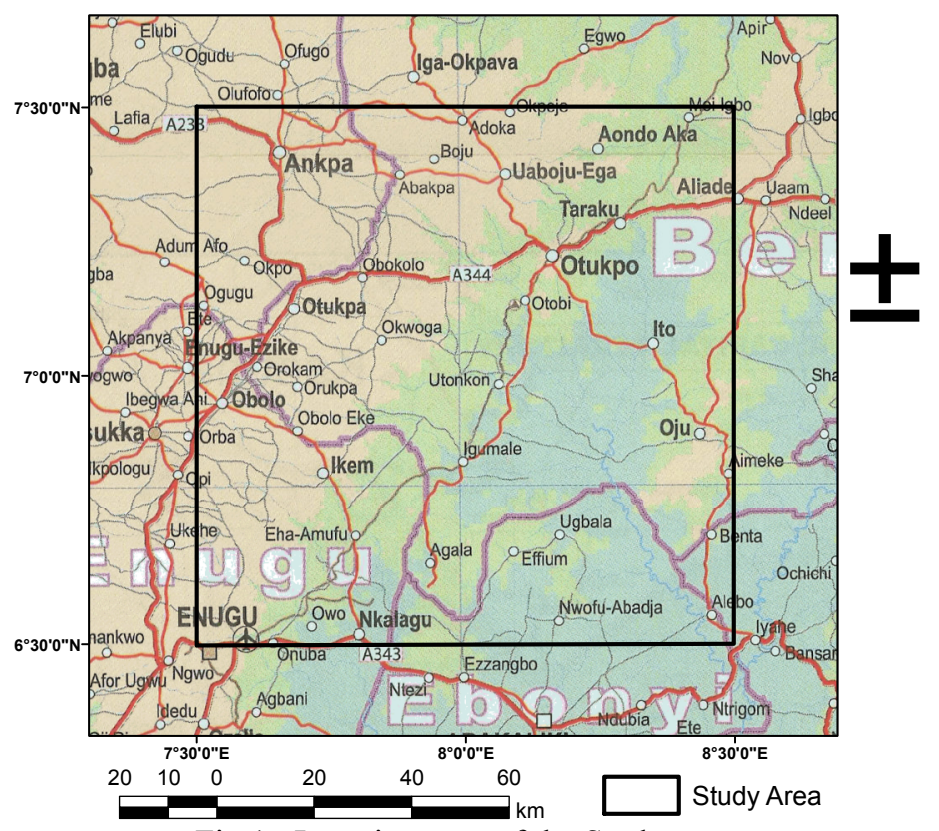

Fig 1.: Location map of the Study area

\section{GEOLOGICAL FRAMEWORK}

Northern Anambra basin is situated in the southeastern part of Nigeria. It is delimited in the north by Nupe basin and eastern by Benue Trough, western the West African massif, and south by Niger Delta (Umeji, 2005). "Chronologically, the studied basin is cretaceous basin, morphologically the basin looks unevenly triangular (Figure 2) and contains about 9km sedimentary infilling, with an area extend of almost 40,100 sq.km. Lateral and Vertical extension resulting from paleoenvironmental setting shows a vast lithologic heterogeneity. (Nwajide and Reijers, 1996 and Reijers and Nwajide, 1998)".

According to Nwajide and Reijers, 1996, sediment accumulation started with paralic shales and CampanianMaastrichtian marine Nkporo Formations, overlaying the Nkporo Formation is the Mamu Formation, this formation contains a coal seam measure which occurs in belts. Ajali and Owelli Formations which lithologically contains the fluvio-deltaic sandstone is a lateral equivalent that lie on the Mamu Formation. Imo and Nsukka Formations (marine shales) overlie the Ajali. The marine shale Nsukka Formation underlined the Eocene sandstone Nanka Formation. Akata shale and Agbada formation in the Niger delta is the Anambra Basin Paleogene equivalents.

Nkporo shales contain Campanian to Maastrichtian saline marsh and fossiliferous pro-deltic facies (Nwajide and Reijers, 1996). Sedimentary infilling of Nkporo Formation reveals a cone-shaped superficial marine condition which sorted into canal of low drive marshes. "Mamu Formation which underlain the Ajali sandstone exist as a band which trendes NS of the Calabar flank, fluctuating west round the Ankpa Plateau and sacking at Idah close to the River Niger". The Ajali Sandstone which overlies the Mamu marks the pinnacle of the regression of which the coastline is still concave. The converging coastal drift cells directed the sedimentary infilling and it revealed the tidal sand waves a classic distinguished fixtures of Ajali Sandstone. The Nsukka Formation and the Imo Shale spot the start of marine lapse in the Anambra Basin in the Paleocene. 


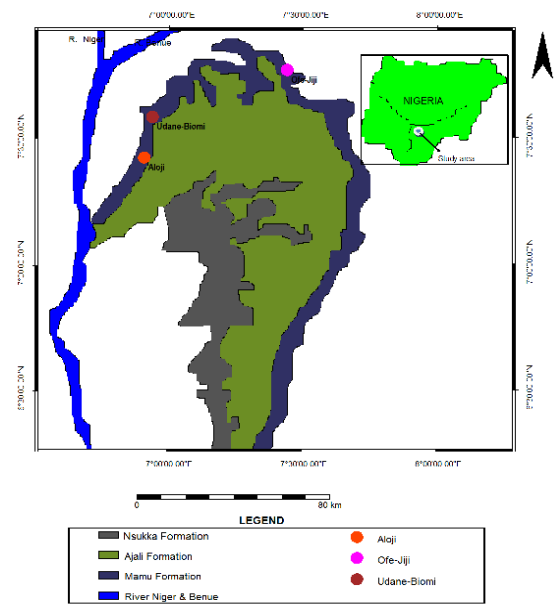

Fig. 2: Geology map of Anambra Basin (Adopted from Umeji, 2005).

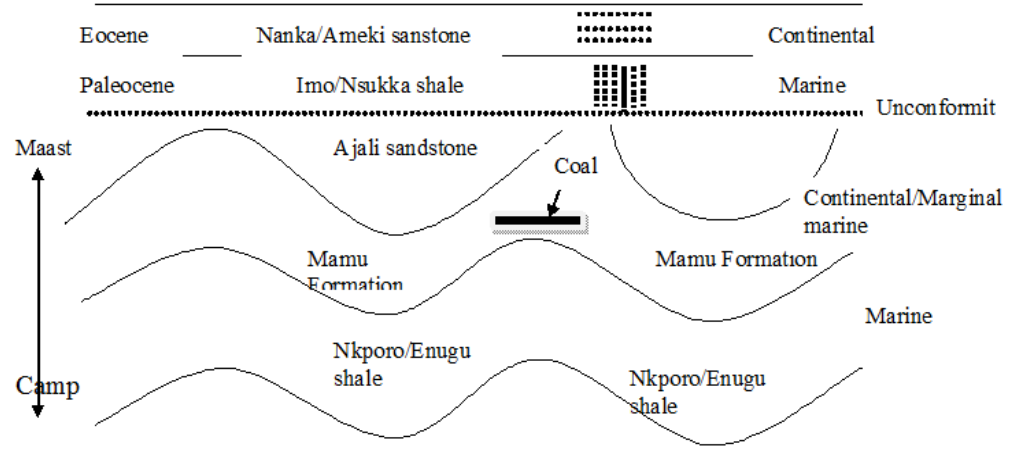

Fig. 3.: Lithostratigraphic structure of Anambra Basin (Adopted from Akande et al, 2012)

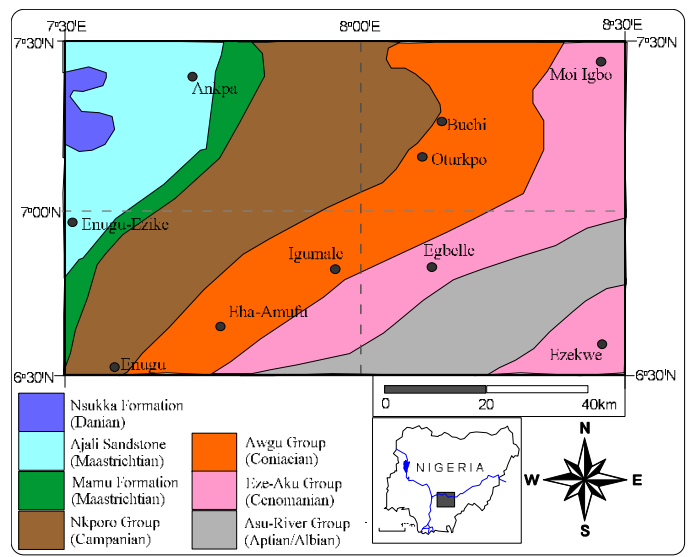

Fig. 4: Local Geology of the Area.

\section{Material and Method \\ Data Acquisition:}

Four sheets of aeromagnetic data (266, 267288 and 289) over Ankpa, Oturkpo, Igumele and Ejekwe area. These data are obtained through purchase from Nigeria Geological Survey Agency Abuja (NGSA). The data was normalized and 80m meters altitude along NS flight lines spaced about 1000 meters apart was maintained during data acquisition. The scale of map obtained is 1: 100,000.

\section{Data Enhancement Techniques}

Usually, it is difficult to interprets a contour TMI anomalous data because of various earth disturbances. Different enhancement technique can help in improving the quality of data. Mathematical filters like downward continuation, upward continuation, first vertical derivative, analytical signal, reduction to the pole, etc. are 
enhancement techniques and they are very important in delineating near surface structures. Although, their limitations are based on data point available and the angle of inclination between the earth's magnetic field the horizontal, also, the magnetic declination between the vertical component and the true north. (Mandal, et al 2015 and 2013).

\section{(a) Upward Continuation}

In upward continuation, the shallow feature (i.e. short-wavelength) anomalies are suppressed and the long-wavelength (deeper sources) anomalies are enhanced. Upward Continuation is a mathematical technique which project data taken at a height to an advanced elevation.

\section{(b) Downward Continuation}

In downward continuation, long-wavelength (deeper magnetic sources) anomalies in magnetic data are suppressed; while the shorter wavelengths (shallow magnetic features) are improved or enhanced. Downward continuation is a mathematical procedure that computes magnetic field at a lower level. This process emphasizes shorter wavelengths, but can be unstable and produces artefacts (Igwesi and umego, 2013).

(c) Reduction to the Pole

Reduction to the pole is a mathematical enhancement filter that changes induced magnetic anomalies from near/or close to the equator to act as if the sources were positioned at the magnetic north pole. Reduction to the pole is a worthwhile and active enhancement aimed at transforming the TMI anomalous data response to create asymmetrical causative body into an anomalous body that is same and would produce same effect if it were situated at/or near the North pole and magnetized by induction only.

"Pole reduction filter makes explanations of the magnetic data like faults much easier because it changes their asymmetric anomalies to symmetric and anti-symmetric forms (Anakwuba et al.,2011 and Ofoha, 2015)".

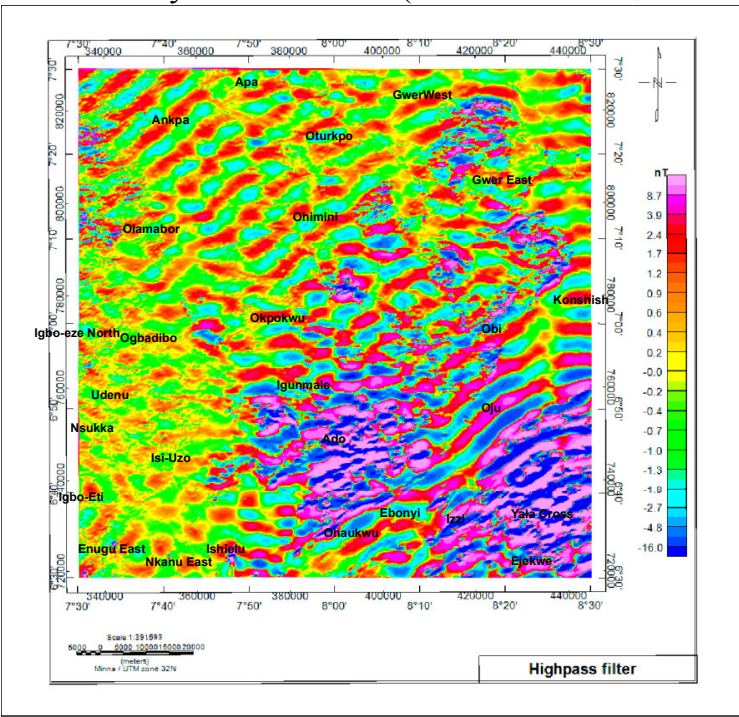

Fig. 5: Skewness of magnetic anomalous body as a result of uneven basal magnetic sources

\section{Results and Discussion}

Method of Interpretation

Qualitative and quantitative methods are used in interpretation. The two methods are discussed below.

\section{Qualitative Interpretation}

Qualitative interpretation of the aeromagnetic data was carried out by physical observation of total magnetic intensity map (TMI), the residual anomalous map, the upward continuation and the magnetic lineament maps. The following features were noted during the qualitative interpretation:

a. The trend of contours.

b. The values of the contours.

c. Maximum and minimum values of the contours and their aerial extent.

d. The direction of the magnetic structures.

The total magnetic intensity map (TMI) which is marked by irregular and spirogyra shaped bodies (fig. 6). The Total Magnetic Intensity map elucidates clearly intensities between -115.2nT and 103.9nT, this map shows magnetic intensities which are high, low or intermediate in magnitude. This can be seen in the colour variations shown in the map and its legend. These intrinsic variations in the study area are attributed to differences in 
subsurface materials and its depth. The irregular shape is as a result of shallow geologic sources.

Also, fig. 7 depicts the reduction to equator map, the magnetic intensity ranges between $-110.8 \mathrm{nT}$ and 87.6nT. The application of RTE (Reduction to Equator) is pertinent, as the study area is within a low latitude zone and its application was because of changes in magnetic intensity with respect to change in time and place. The residual map (fig. 8) is noticeable by spirogyra and uneven shaped bodies described by lows, highs and medium magnetic intensities. Around latitude $7^{\circ} 18^{\prime} \mathrm{N}$ to $7^{\circ} 30^{\prime} \mathrm{N}$ and longitude $7^{\circ} 30^{\prime} \mathrm{E}$ to $8^{\circ} 05^{\prime} \mathrm{E}$ in the NorthEastern part of the residual anomaly map shows a clear high magnetic intensity. Similarly, between latitude $6^{\circ} 44^{\prime} \mathrm{N}$ to $6^{\circ} 52^{\prime} \mathrm{N}$ and longitude $7^{\circ} 30^{\prime} \mathrm{E}$ to $8^{\circ} 30^{\prime} \mathrm{E}$ at the South-Western part, high magnetic intensity was delineated by the residual anomaly map of the area with a few drop-like bodies at the down south part and settling at the South-Eastern part with the lowest magnetic intensity precisely Yala Cross as the town in between them, the drop-like bodies behaved like remnant bodies that migrated from the middle to the right of the study area.

The magnetic intensities at these zones were summed to be $41.6 \mathrm{nT}$ on the average. This suggests geologic sources of basement origin. The TMI anomaly map shows Igumale, Oju and Ejekwe to contain of noisier magnetic sources as against other towns which suggests igneous intrusions. The anomalies in the study area have the major trends to be South-East to South-West and North-West.

High-pass filter tempers frequencies which are lower than the cut-off frequency and it then passes higher frequencies signals greater than the cut-off frequencies. The high pass filter map shown in Fig. 9 depicts anomalies between the range $-16.0 \mathrm{nT}$ and $8.7 \mathrm{nT}$. The highest and lowest magnetic intensities dominated the map at the South-East part and sparing distributed at the Nortth-East direction. A low-pass filter enhances the data by passing signals with low-frequency but tempers signals with higher frequencies than the cut-off frequency. "The purpose of low-pass filtering is to remove unwanted high frequencies (Singh and Biswas, 2016 and Nwankwo et al, 2008)". The low pass filter map is shown in Fig. 10 which depicts anomalies between the range -109.0nT and 87.3nT. More of the high frequencies were smoothed out when compared with the Total Magnetic Intensity (TMI) map shown in Fig. 6. Smoothing out the high frequencies discovered more of the low frequencies which depict deeper sources. The map is four sectioned having the first section predominantly green with trace of light-yellow layer separating it from the second part.

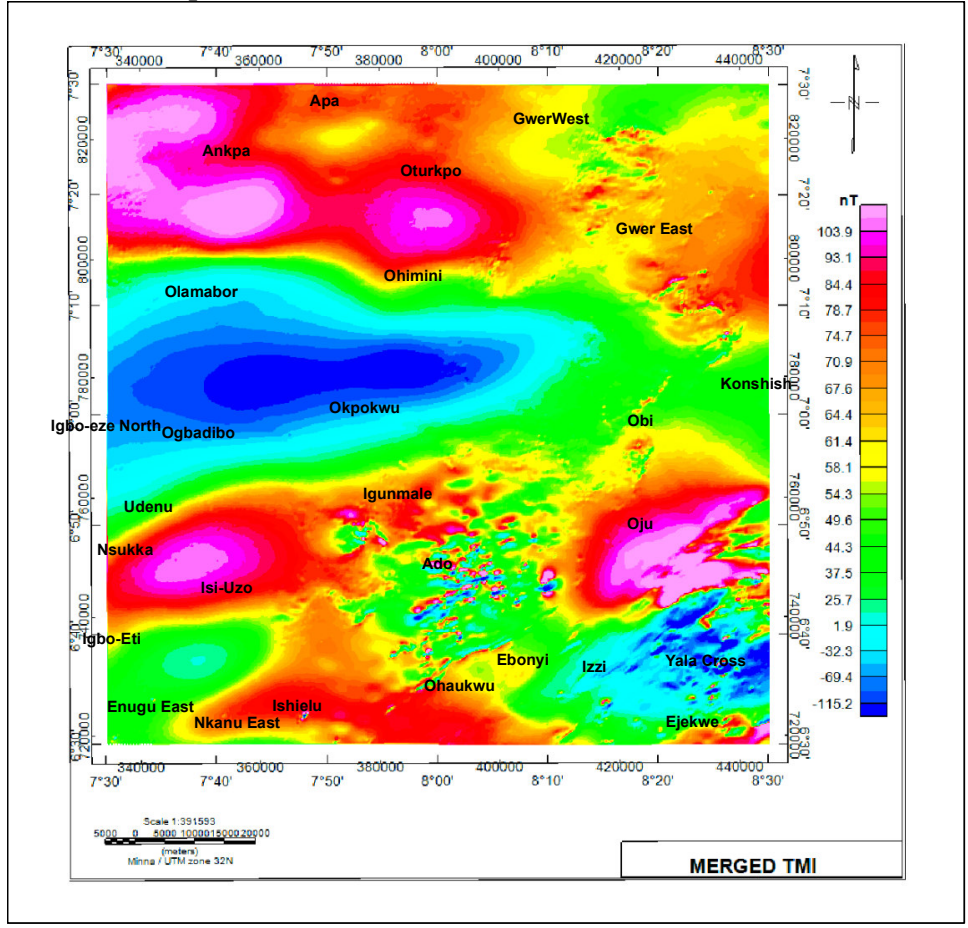

Fig. 6: Merged total magnetic intensity map (TMI) 


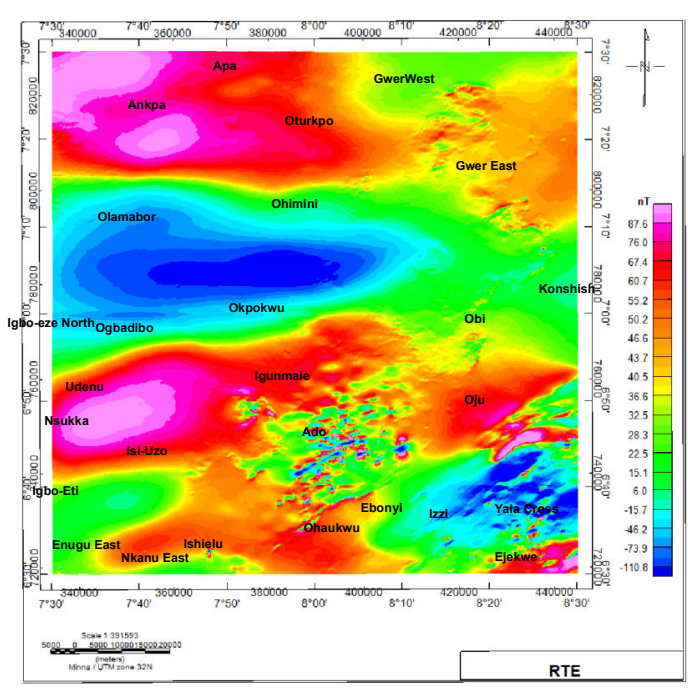

Fig. 7: Reduction to Equator map

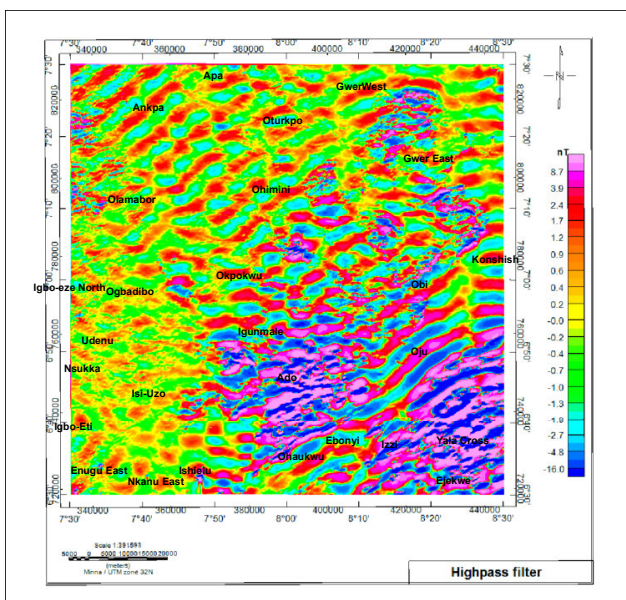

Fig. 9: High-Pass Filter

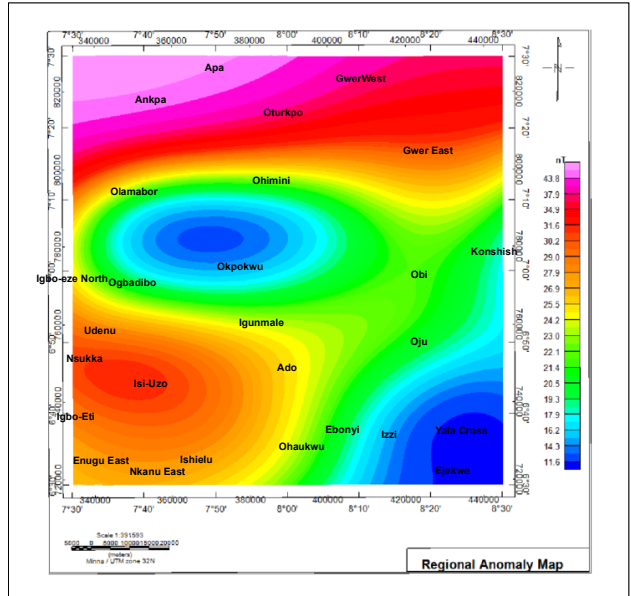

Fig. 8: Regional Anomaly Map

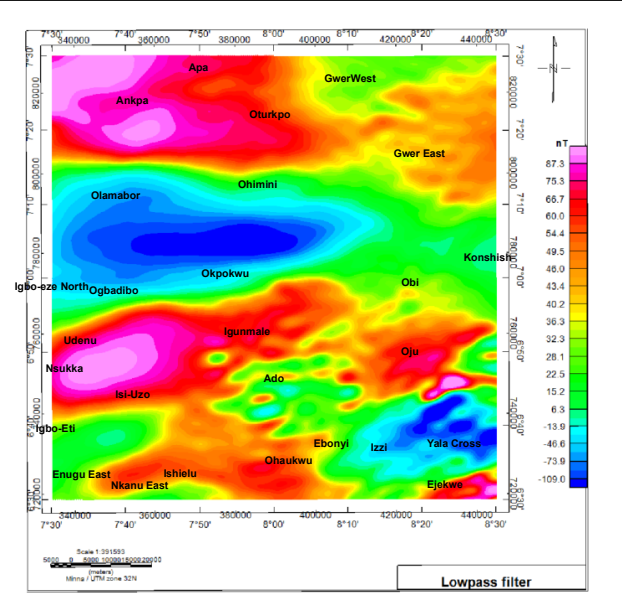

Fig. 10: Low-Pass Filter

\section{Quantitative Interpretation}

Depth to magnetic sources, its shape and size, subsurface temperature and probably details about the susceptibility of the magnetic sources are basic reason for quantitative interpretation (Biswas 2015 and Bemsen et al 2013). The vital parameter in quantitative interpretation is depth to the caustic body. Other parameters like temperature (or heat) and susceptibility are secondary. The shape of the anomaly contains information on depth to source of the anomaly. Due to the clear significance of the sedimentary thickness to the petroleum geophysicist, the depth to source normally called the depth to the basal rock, is of great importance. Depth information may also be imperative when delineating for mineral deposit that are cover by thick consolidated or unconsolidated sedimentary infillings.

To characterized the basin geometry, the basal depth, depth to centroid, depth to base (or depth to bottom) of magnetic source which is known as Curie point depth are of great importance.

Spectral analysis method is used in the depth calculation. The first step to this is to reveal our anomalous bodies in the studied area. To achieve this six profile lines were drawn on the residual anomaly map (fig. 3). The reason for choosing this method is due to its advantage of filtering the noise and enhance the data; and in this process, no information is lost during processing and it show fair representative of the entire area. 


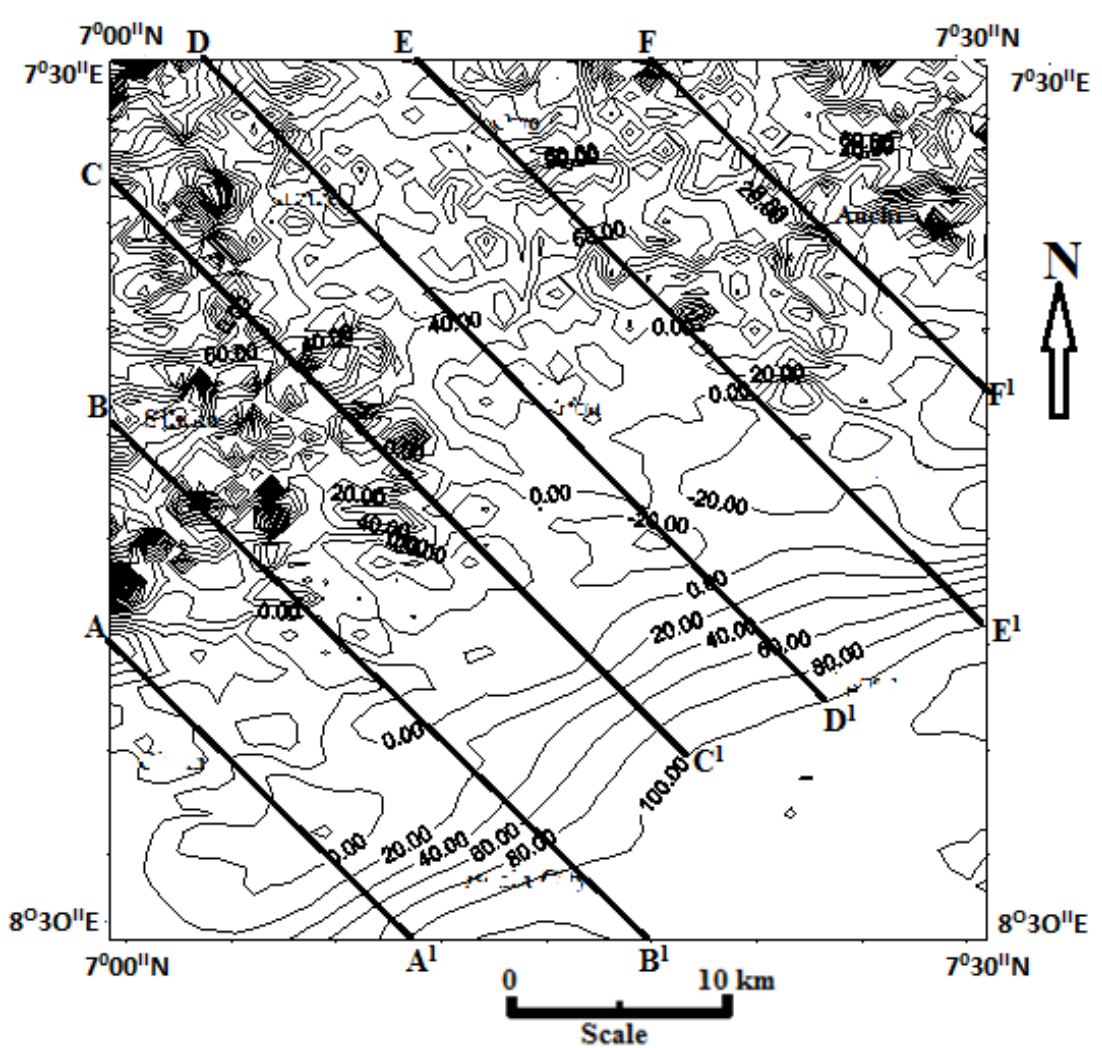

Fig. 11: Profile Lines Draw in the Residual Anomaly Map (10 nT Interval)

Six (6) profile lines, namely A-A', B-B', C-C', D-D', E-E' and F-F' were taken and used for detailed interpretation (see fig. 12). The cross-sections are taken perpendicular to the direction of the contours so as to obtain clear information about the anomalies.

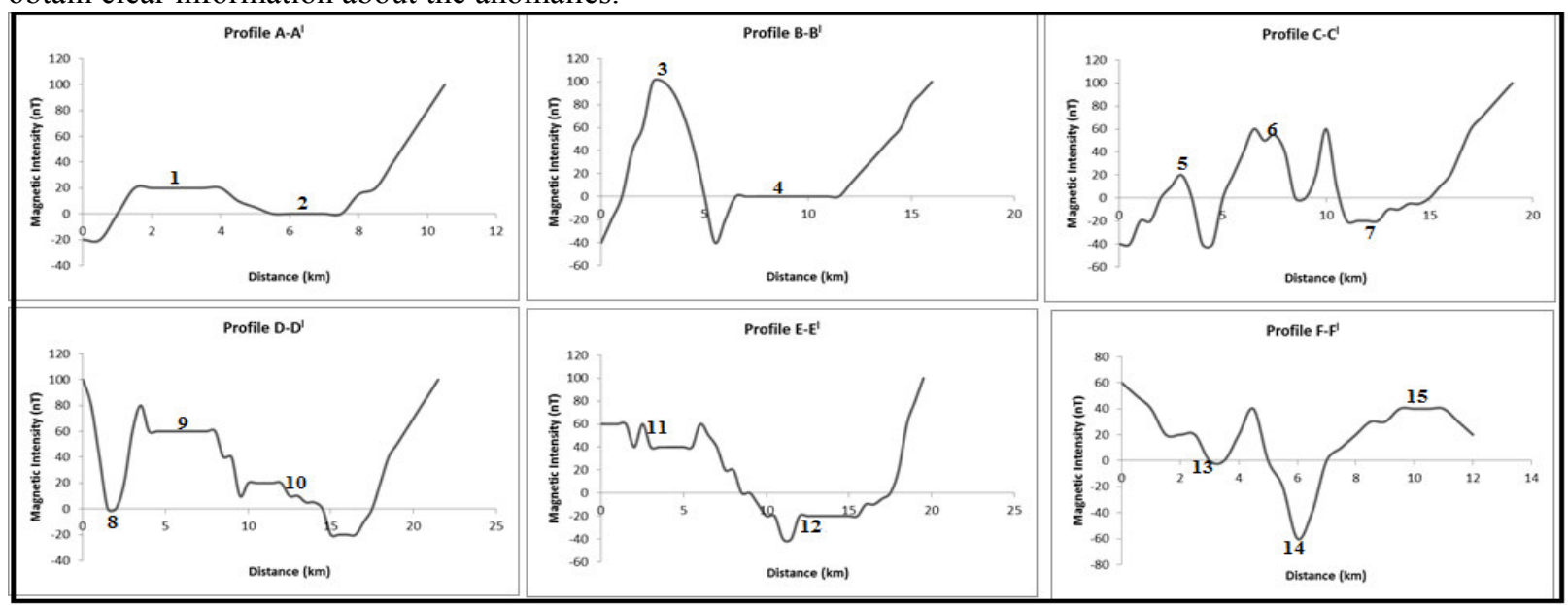

Fig.12: Analysis of the Six Profiles Line Revealing the Anomalous Body

Spectral graphs were then obtained. The power spectrum graphs are natural logarithms plot of natural amplitude against frequencies gotten for the profiles. Linear sections from the low frequency part of the spectral, represents an causative bodies that in deeply seated, this is gotten from each graph. Each graph has two-line segments: the first line gives the depth to centroid (Zo) which is gotten by fitting a trend line through the low wave number part of the radially averaged power spectrum (RAPS).

The gradient of the linear segments was calculated and the basal depth ( $\mathrm{Zo}$ and $\mathrm{Zt}$ ) were determined (fig 13a-d) (Bhattacharyya, 1966 and Bhattacharyya et al 1975). The graphs obtained are negative because in spectral analysis, the graph decreases as the frequency increases. Hence, the gradients of the line segments must also be negative. The points outside the line segments represent noise (Anudu et al, 2012). 


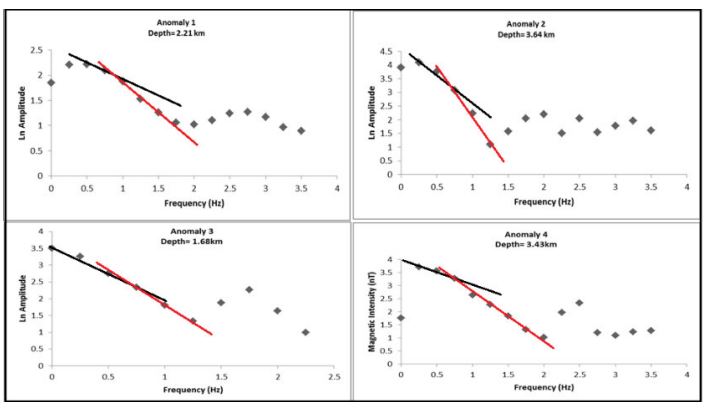

Fig. 13a: Amplitude Spectral for Anomalies 1-4

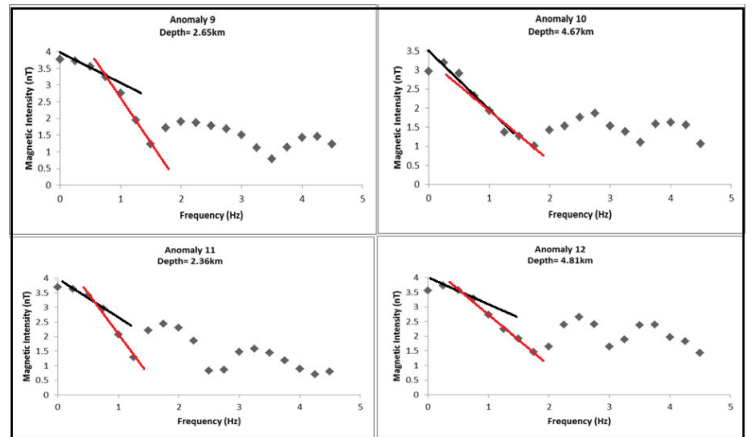

Fig. 13c: Amplitude Spectral for Anomalies 9-12

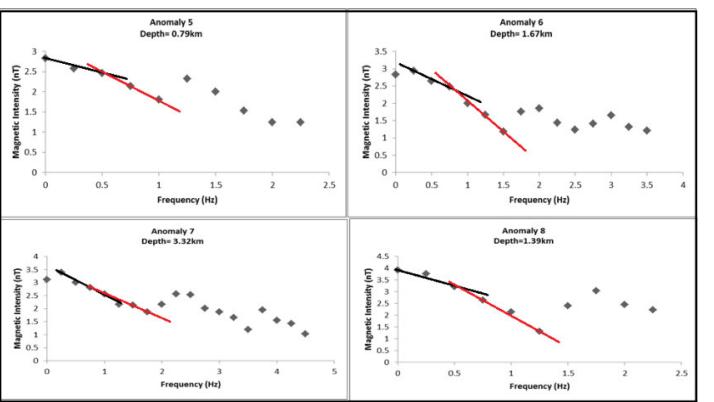

Fig. 13b: Amplitude Spectral for Anomalies 5-8

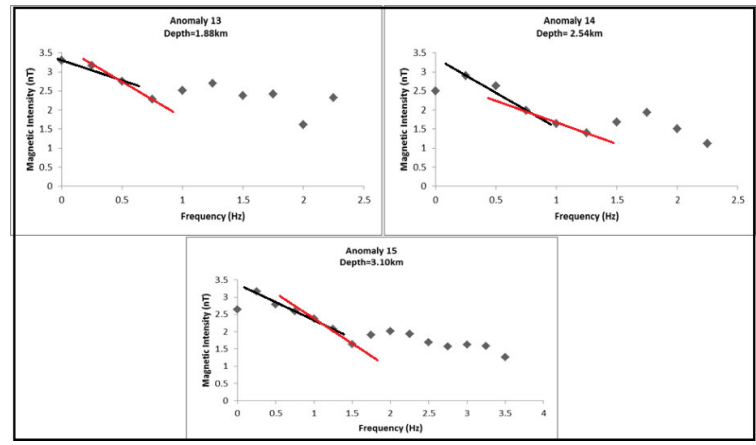

Fig. 13d: Amplitude Spectral for Anomalies 13-15

Table 4.1: Depth Calculation Result

\begin{tabular}{|c|c|c|c|}
\hline Name of Profile & Direction & $\begin{array}{l}\text { No of } \\
\text { Anomaly }\end{array}$ & $\begin{array}{l}\text { Depth in } \\
\mathrm{Km}\end{array}$ \\
\hline \multirow[t]{2}{*}{$\mathrm{A}-\mathrm{A}^{1}$} & NW-SE & 1 & 2.21 \\
\hline & NW-SE & 2 & 3.64 \\
\hline \multirow[t]{2}{*}{$\mathrm{B}-\mathrm{B}^{1}$} & NW-SE & 3 & 1.64 \\
\hline & NW-SE & 4 & 3.43 \\
\hline \multirow[t]{3}{*}{$C-C^{l}$} & NW-SE & 5 & 0.79 \\
\hline & NW-SE & 6 & 1.67 \\
\hline & NW-SE & 7 & 3.32 \\
\hline \multirow[t]{3}{*}{$\mathrm{D}-\mathrm{D}^{1}$} & NW-SE & 8 & 1.39 \\
\hline & NW-SE & 9 & 2.65 \\
\hline & NW-SE & 10 & 4.67 \\
\hline \multirow[t]{5}{*}{$E-E$} & NW-SE & 11 & 2.36 \\
\hline & NW-SE & 12 & 4.81 \\
\hline & NW-SE & 13 & 1.88 \\
\hline & NW-SE & 14 & 2.54 \\
\hline & NW-SE & 15 & 3.1 \\
\hline
\end{tabular}

\section{Basement Topography}

From the calculated depth values gotten two depth sources were model. The deep seated magnetic anomaly sources that ranges 2.40 to $4.30 \mathrm{~km}$ and the shallower magnetic depth sources ranging from 0.58 to $1.76 \mathrm{~km}$ (Fig 14). Deep seated magnetic sources may possibly denote depths to ancient Pre-Cambrian basement, while the shallower magnetic sources (thinner sedimentary infilling) will possible represents basement intrusion and/or magnetized ore bodies with little sedimentary infillings. The basal depth is deeper in the northern and mid part of the study area trending northwest-southeast direction and we have thinner sedimentary infilling in the eastern and southern parts.

3-D surface plot shows the basin configuration clearly, there is a linear trough at the central part of the study area indicating thicker sediments which trend northwest-southeast direction while the eastern and southern parts have shallower sedimentary thicknesses (see Fig. 15). 


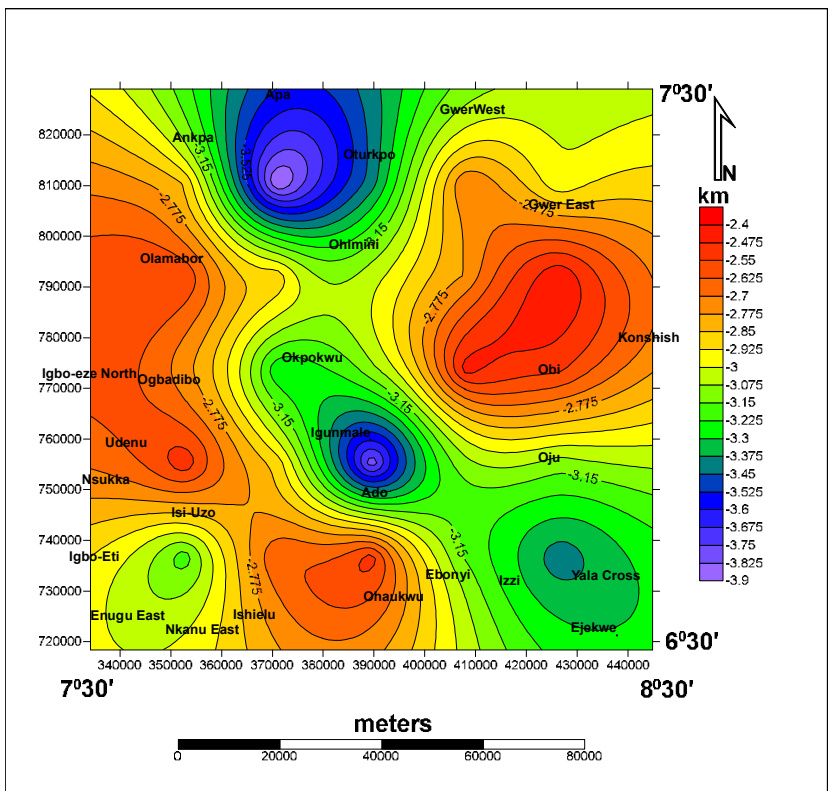

Fig. 14: Map showing the depth to the deep seated source (Z1) Anomaly from the spectral Analysis

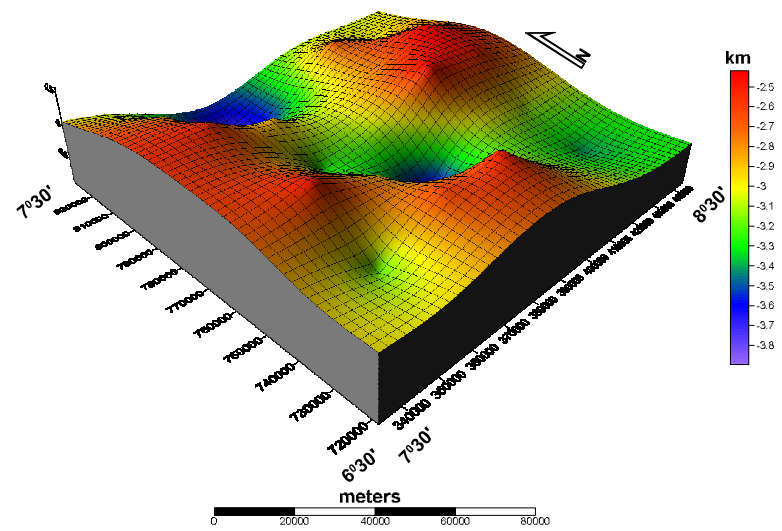

Fig. 15: $3 \mathrm{~d}$ map of the basement from the deeper anomaly source (Z1)

\section{Geologic Models Generated}

Geologic models for the magnetic anomalies were constructed using Geo-modelling softwares. The details of the modelling can be seen below:

\section{Profile A-A $\mathbf{A}^{\mathbf{1}}$}

This profile cut across Igunmale area in the south-western part. It cuts part of sheet 288 . The highest magnetic reading within this profile is $41 \mathrm{nT}$ and the lowest is $26 \mathrm{nT}$ (Fig.16a). The basal depth value within this profile range from $1.5 \mathrm{~km}$ to $3.5 \mathrm{~km}$ (Fig. 16a).

\section{Profile B- $\mathbf{B}^{1}$}

The highest magnetic value within this profile is $80 \mathrm{nT}$ and the lowest is $-20 \mathrm{nT}$. The basal depth reading ranges from $1.5 \mathrm{~km}$ to $4.21 \mathrm{~km}$ (Fig. 16b). The extensive part of the profile which is anomaly 4 indicates deeper magnetic source while the shallowest part is found in anomaly 4 with depth of $1.5 \mathrm{~km}$.

\section{Profile C-C $\mathbf{C}^{1}$}

This profile cuts across the north-western, mid, and south-eastern parts of the study area (Ankpa and Ejekwe). The area shows high magnetic reading which depicts shower sedimentary highest magnetic intensity value along this profile is $130 \mathrm{nT}$ and the lowest is $-40 \mathrm{nT}$. The basal depth ranges from $1.5 \mathrm{~km}$ to $3.5 \mathrm{~km}$.

\section{Profile D-D ${ }^{1}$}

This profile passes through Ankpa and Ejekwe respectively, the profile run through the southern part of our studied area. The area shows high magnetic value which depicts shower sedimentary infilling. The highest magnetic intensity reading is $160 \mathrm{nT}$, while the lowest is $-100 \mathrm{nT}$. The depth values ranges from $1.2 \mathrm{~km}$ to $3.37 \mathrm{~km}$. Profile E-E ${ }^{1}$

This profile cuts through the north-eastern part of the study area (Oturkpo). The highest magnetic value is 200nT 
and the lowest is $2 \mathrm{nT}$. The basal depth values ranges from $1.0 \mathrm{~km}$ to $5.08 \mathrm{~km}$.

\section{Profile F-F ${ }^{1}$}

This profile cuts through the north-eastern part of the study area (Oturkpo). The higest magnetic value is 150nT and the lowest is $10 \mathrm{nT}$. The basal depth values averaging about $4 \mathrm{~km}$.
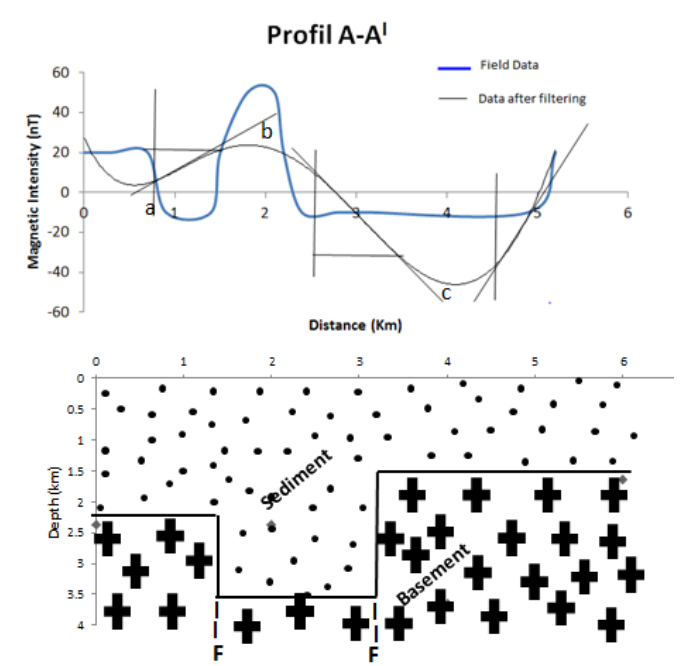

Fig.16a: Model Geological Section along Profile A-A ${ }^{1}$

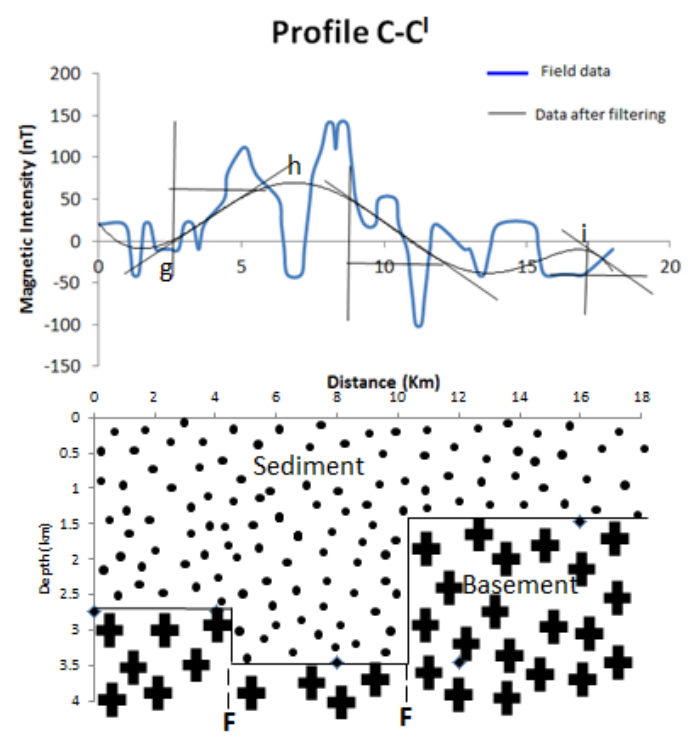

Fig.16c: Model Geological Section along Profile C-C

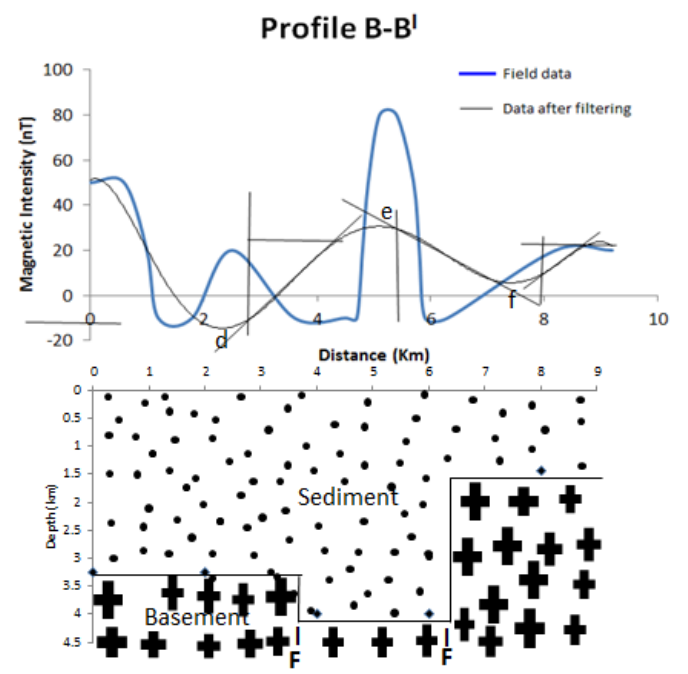

Fig.16b:Model Geological Section along Profile B-B ${ }^{1}$

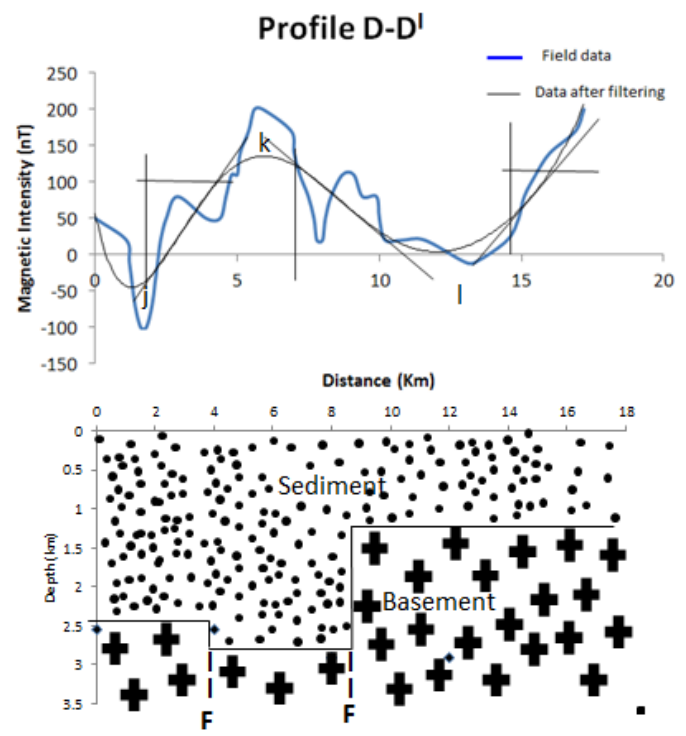

Fig.16d:Model Geological Section along Profile D-D ${ }^{1}$ 


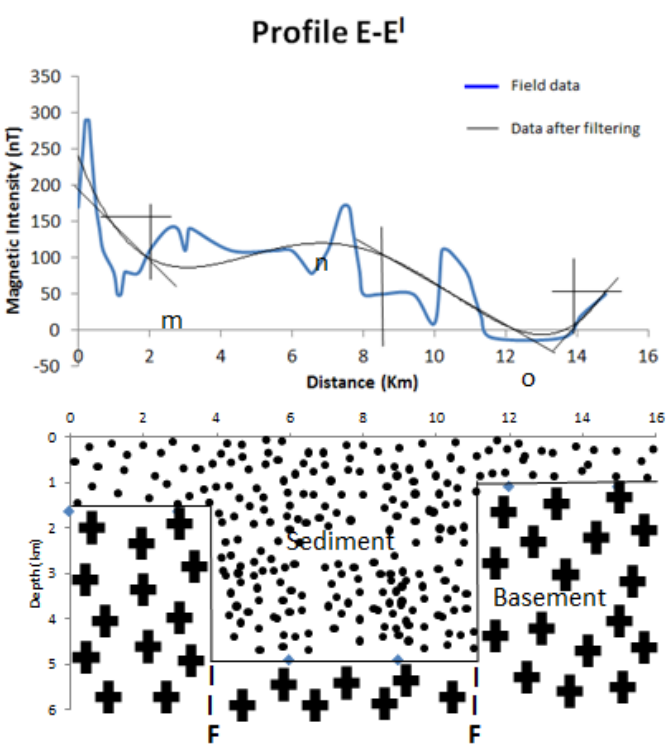

Fig.16e: Model Geological Section along Profile E-E ${ }^{1}$
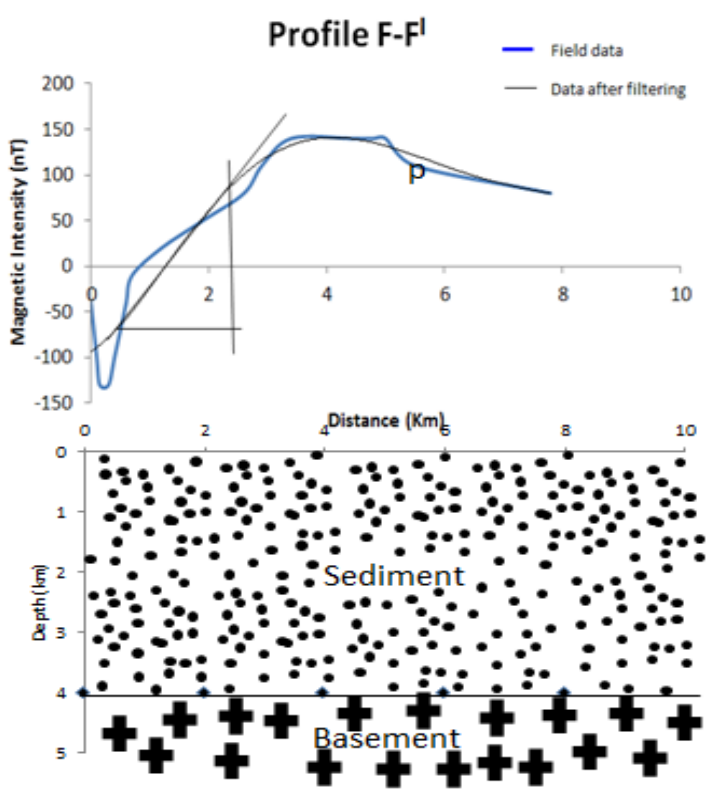

Fig.16f: Model Geological Section along Profile F-F ${ }^{1}$

\section{Conclusions}

Qualitatively, the Aeromagnetic data over Ankpa, Oturkpo, Igumale and Ejekwe areas have been enhancement, digitized and interpreted. The data was analyzed quantitatively by Spectral analysis. The results obtained from the qualitative interpretation showed geologic boundaries on Reduction to Equator and the Upward Continuation map at $10 \mathrm{~km}$ gave a clear difference between boundaries of the same but different anomalous bodies within the study area.

The high pass filter map is shown in Fig. 9 which depicts anomalies between the range $-16.0 \mathrm{nT}$ and $8.7 \mathrm{nT}$. The Low Pass filters are shown Fig. 10 depict anomalies that range from -109.0nT to 87.3nT respectively. The Upward Continuation Map at 10km depicts anomalies that range from $-21.9 \mathrm{nT}$ to $54.9 \mathrm{nT}$. It can be seen from the upward continuation maps that the higher the distance of the upward continuation map the more the higher frequencies are smoothed out revealing more of the low frequencies.

Depth calculation was carried out using Spectral analysis method and it has proven to be a power quantitative tool in analyzing space data. The result reveals two depth seated sources in the study area; the deeper magnetic seated sources (Thicker sedimentary infilling) which ranges from $1.76-4.5 \mathrm{~km}$, and the shallower basal sources (thinner sedimentary infilling) which ranges from $0.58-1.76 \mathrm{~km}$. The basal depths are farther in the northern and central parts trending northwest-southeast direction and its shallower (thinner sedimentary cover) in the eastern and southern parts of the study area. The quantitative result also reveals a trough which can help in sedimentary accumulation trending northwest-southeast, this direction conforms to the direction of the structure in the area. Again, the general trend of the lineament is Northeast-Southwest, minor one's trending in East-West directions. From the sedimentary thicknesses $(0.58-4.5 \mathrm{~km})$, the depth model, depth calculation and the base geometry obtained from this study, there is a possibility solid mineral accumulation in the northwest and southeastern part of the studied area.

\section{Recommendation}

Since no single geophysical method is ever conclusive, there is a great need to integrate more geophysical methods in other to reveal clearly the zones of good mineral and hydrocarbon potential of the study area.

\section{References}

[1] Akande S.O., Egenhoff, S.O., Obaje, N.G., Ojo, O.J., Adekeye, O.A., and Ertmann, B.D. (2012). Hydrocarbon potential of Cretaceous sediments in the Lower and Middle Benue Trough, Nigeria: Insights from new source rock facies 34-47.

[2] Anakwuba, E.K., Onwuemesi, A.G., Chinwuko, A. I. and Onuba, L. N. (2011). The Interpretation of Aeromagnetic anomalies over Maiduguri - Dikwa depression, Chad Basin Nigeria: A Structural View. Scholars research library. Archives of Applied Science Research, vol. 3, No.4, pp. 499-508.

[3] Anudu, G.K., Onuba, L.N., Onwuemesi, A.G. and Ikpokonte, A.E. (2012). Analysis of aeromagnetic 
data over Wamba and its adjoining areas in north-central Nigeria. Earth Sci. Res. Journ., vol. 16, no. 1, pp. $25-33$.

[4] Biswas, A. (2017). Inversion of source parameters from magnetic anomalies for mineral ore deposits exploration using global optimization technique and analysis of uncertainty. Natural Resources Research, (DOI: 10.1007/s11053-017-9339-2)

[5] Biswas, A. (2015). Interpretation of residual gravity anomaly caused by a simple shaped body using very fast simulated annealing global optimization. Geoscience Frontiers, 6(6), pp 875-893.

[6] Bhattacharyya, B.K. (1966). Continuous spectrum of the magnetic field anomaly dueto a rectangular prismatic body. Geophysics, vol. 31, pp. 121.

[7] Bhattacharyya, B.K. and Leu, L.K. (1975). Spectral analysis of gravity and magneticanomalies due to two-dimensional structures. Geophysics, vol.40, pp.993-1003.

[8] Bemsen, I.E., A.E. Onuemesi, E.K. Anakwuba A.F. Chinwuko, A.O.Usman andC.C. Okonkwo, 2013. Spectral Analysis of Aeromagnetic Data over part of the Southern Bida Basin West-Central Nigeria.International Journal of Fundamental Physical Sciences, 3(2): 27-31.

[9] Fuller, B.D., 1967. Two-dimensional frequency analysis and design of grid operators. In: Mining geophysics, Society of Exploration Geophysicists, Tulsa, 658-708

[10] Gibson, R.I. \& Millegan, P.S. (eds) (1998) Geologic Applications of Gravity and Magnetics: Case Histories. SEG Reference Series 8 \& AAPG Studies in Geology 43,Tulsa.

[11] Grant, F.S., 1985. Aeromagnetics, geology and ore environments, I. Magnetite in igneous, sedimentary and metamorphic rocks: An overview. Geoexploration, 23: 303-333.

[12] Igwesi, D.I., and Umego, M.N. (2013). Interpretation of Aeromagnetic Anomalies over some parts of Lower Benue Trough using Spectral Analysis Technique. International Journal of Scientific and Techn. Research, Vol. 2, no. 8, pp. 153-165.

[13] Likkason, O.K. (2007). Angular spectral analysis of aeromagnetic data over the Middle Benue Trough, Nigeria. Journal of Mining and Geology, vol. 43, no. 1, pp. 53 - 62.

[14] Mandal, A., Mohanty, W. K., Sharma, S. P., Biswas, A., Sen, J., Bhatt, A. K. (2015). Geophysical signatures of uranium mineralization and its subsurface validation at Beldih, Purulia District, West Bengal, India: A case study. Geophysical Prospecting, 63, pp 713-726.

[15] Mandal, A., Biswas, A., Mittal, S., Mohanty, W. K., Sharma, S. P. Sengupta, D., Sen, J., Bhatt, A. K. (2013). Geophysical anomalies associated with uranium mineralization from Beldih mine, South Purulia Shear Zone, India. Journal Geological Society of India, 82(6), pp 601-606.

[16] Nwajide, C. S. and Reijers, T. J. A. (1996). Geology of the Southern Anambra Basin. In: Reijers, T. J. A. (Ed), Selected chapters on Geology, SPDC, Warri, pp.133-148.

[17] Ofoha, C. C., (2015). Geological Interpretation Inferred from a High Resolution Aeromagnetic Data over parts of Mmaku and Environs, Southeastern Nigeria, International journal of Applied Science and Mathematical Theory, Vol.1 No 4.

[18] Onwuemesi, A.G. (1997). One Dimensional Spectral Analysis of Aeromagnetic Anomalies and Curie Depth Isotherm in the Anambra Basin of Nigeria. Journal of Geodynamics, vol. 23, No.2, pp. 95107.

[19] Reijers, T. J. A and Nwajide, C. S. (1998). Geology of the Southern Anambra Basin. Unpublshed Report for Chevron Nigeria Limited, Field Course Note 66p.

[20] Singh, A., Biswas, A. (2016). Application of global particle swarm optimization for inversion of residual gravity anomalies over geological bodies with idealized geometries. Natural Resources Research, 25(3), pp 297-314.

[21] Spector A. and Grant, F.S. (1970). Statistical Models for interpreting Aeromagnetic Data. Geophysics, vol. 35 , pp. $2983-3002$.

[22] Umeji, P. O. (2005). Palynological study of the Okaba coal section in the Anambra Basin, Southern Nigeria, Journ. of Mining and Geol. 41(2), pp. 194. 